\title{
PERBANDINGAN KebUtUHAN BESI STRUKTUR BALOK,KOLOM DAN PELAT DI AS BUILT DRAYING TERHADAP DESAIN KONDISI BALANCE
}

\author{
Arifien Nursandah ${ }^{1}$ ), Didik dwi juniarto ${ }^{2)}$ \\ 1) Progam Studi Teknik Sipil, Fakultas Teknik, \\ Universitas Muhammadiyah Surabaya \\ J1.Suorejo No.59 surabaya, Telp 031-3811966 \\ Email: arifien.nursandahums@gmail.com \\ 2) Progam Studi Teknik Sipil, Fakultas Teknik, \\ Universitas Muhammadiyah Surabaya \\ J1.Suorejo No.59 surabaya, Telp 031-3811966 \\ Email: didkdije93@gmail.com
}

\begin{abstract}
This final project discussed a comparison steel of school buildings at Surabaya, by comparing steel in Asbuilt drawing used in field to theory of reinforced concrete structure calculation, so that it could be known whether the using of steel is enough, less or over. In this comparison process we used 30 samples and 3 counting variables i.e. steel on beam structure, column and plate floor of 3thstorey on construction, Statistical model used was normal distribution with parametric and nonparametric statistics so that it could be used one sample $\mathrm{T}$ test and sign test (binomial test), using SPSS application. The reference comparison, we was take the calculation of per1 $\mathrm{m}^{3}$ samples on columns and beams and per $1 \mathrm{~m}^{2}$ on floor plates, against theoretical calculation referring to the provision of SNI 2847-2013.
\end{abstract}

Keywrds: Design balance condition, Parametric Statistics

\begin{abstract}
Abstrak
Tugas akhir ini membahas mengenai perbandingan penggunaan besi pada gedung seokolah yang ada di Surabaya , membandingan pemakaian besi pada gambar Asbuilt drawing yang di pakai di lapangan dengan desain perhitungan struktur balance, sehingga di rasa mengetahui selama ini pemakaian besi cukup, kurang atau over.Pada proses perbandingan ini kita menggunakan 30 sampel dan 3 variabel pehitungan yaitu ; besi pada struktur balok, kolom dan pelat lantai pada konstrusi 3 lantai,Model statistik yang digunakan adalah distribusi normaldengan statistik parametik dan nonparametik sehingga dapat di gunakan uji $\mathrm{T}$ satu sampel dan uji tanda (uji Binomial), menggunakan apilkasi SPSS.Acuan perbandingan yang kita ambil adalah perhitungan sampel per1 $\mathrm{m}^{3}$ pada kolom dan balok serta per $1 \mathrm{~m}^{2}$ pada pelat lantai, terhadap perhitungan secara teori yang mengacu pada ketentuan SNI 2847-2013.
\end{abstract}

Kata Kunci: Desain balance, Statistik parametik

\section{PENDAHULUAN}

Struktur bangunan pada umumnya terdiri dari struktur bawah dan struktur atas. Struktur bawah yang dimaksud adalah pondasi dan struktur bangunan yang berada di bawah permukaan tanah, sedangkan yang dimaksud dengan struktur atas adalah struktur bangunan yang berada di atas permukaan tanah seperti kolom, balok, plat, tangga. Setiap komponen tersebut memiliki fungsi yang berbedabeda di dalam sebuah struktur.

Fungsi utama besi tulangan pada struktur beton bertulang yaitu untuk menahan gaya tarik.Oleh karena itu pada struktur balok, pelat, kolom ataupun struktur lainnya dari bahan beton bertulang, selalu diupayakan agar tulangan longitudinal (memanjang) dipasang pada seratserat beton yang mengalami tegangan tarik.

Keadaan ini terjadi terutama pada daerah yang menahan momen lentur besar (umumnya di daerah lapangan/tengah bentang, atau di atas tumpuan), sehingga sering mengakibatkan terjadinya retakan beton akibat tegangan lentur tersebut.
Beban-beban yang bekerja pada struktur seperti beban mati (dead load), beban hidup (live load), beban gempa(earthquake), dan beban angin (wind load) menjadi bahan perhitungan awal dalam perencanaan struktur untuk mendapatkan besar dan arah gaya-gaya yang bekerja pada setiap komponen struktur, kemudian dapat dilakukan analisis struktur untuk mengetahui besarnya kapasitas penampang dan tulangan yang dibutuhkan oleh masingmasing struktur.

Perencanaan srtuktur yang di lakukan mengacu pada peraturan atau pedoman standar yang mengatur perencanaan dan pelaksanaan bangunan beton bertulang, yaitu Standar Tata Cara Penghitungan Struktur Beton nomor: SK SNI 2847:2013

Pada realitanya di lapangan banyak kasus yang terjadi proporsi pemakaian besi yang tidak seimbang antara desain srtuktur dengan teori perancangan sehingga mengakibatkan pemakain besi yang terlalu banyak atau pemakaian besi yang terlalu irit. 
Dengan keadaan realita seperti di atas maka tugas akhir ini mencoba untuk menganalisa penggunaanbesi pada banggunan sekolah menengah pertama yang ada di surabaya dengan membandingkan kebutuhan besi yang ada pada desain penulangan beton dilapangan dengan perhitungan teori permodelan.

Rumusan maslah yang dapat dirumuskan pada penulisan tugas akhir ini adalah sebagai berikut :

1. Bagaimana kebutuhan tulangan struktur balok, kolom dan pelat pada gedung SMP di Surabaya berdasarkan teori perencanaan struktur?

2. Bagaimana pengaplikasian pemakaian tulagan struktur balok, kolom dan pelat pelat pada gedung SMP di Surabaya berdasarkan data lapangan ?

3. Bagaimana perbandingan antara teori perencanaan dan aplikasi di lapangan dari kebutuhan tulangan struktur balok, kolom dan pelat pada gedung SMP di Surabaya berdasarkan Uji statistik?

Tujuan dari penelitian ini adalah:

1. Untuk mengetahui kebutuhan tulangan struktur balok, kolom dan pelat pada gedung SMP di Surabaya berdasarkan teori perencanaan struktur

2. Untuk mengetahui pengaplikasian pemakaian tulagan struktur balok, kolom dan pelat pelat pada gedung SMP di Surabaya berdasarkan data lapangan

3. Untuk mengetahui perbandingan antara teori perencanaan dan aplikasi di lapangan dari kebutuhan tulangan struktur balok, kolom dan pelat pada gedung SMP di Surabaya berdasarkan Uji statistic.

\section{TINJAUAN PUSTAKA \\ Dasar Perencanaan}

Peraturan yang di pakai dalam proses perencanaan ini adalah sebagai berikut:

$>$ Perhitungan kekuatan beton bertulangan menggunakan persyaratan beton bertulang struktural untuk bangunan gedung SNI-28472013.

$>$ Perhitungan pembebanan menggunakan peratur pembebanan Indonesia untuk gedung PPUIG 1983, dan juga menggunakan SNI-1727-2013.

\section{Beban Hidup}

Beban Hidup adalabeban yang diakibatkan oleh pengguna dan penghuni bangunan gedung atau struktur lain yang tidak termasuk beban konstruksi dan beban lingkungan, seperti beban angin, beban hujan, beban geMPa, beban banjir.SNI-1727-2013 Pasal.4.1

Tabel 1. Beban hidup

\begin{tabular}{lcc}
\hline Beban hidup & \multicolumn{2}{c}{ Berat } \\
\hline Atap & 100 & $\mathrm{Kg} / \mathrm{m}^{3}$ \\
\hline Lantai sekolah & 250 & $\mathrm{Kg} / \mathrm{m}^{3}$ \\
\hline
\end{tabular}

Sumber :PPIUG 1983

\section{Beban mati}

Beban mati adalah berat seluruh bahan konstruksi bangunan gedung yang terpasang, termasuk dinding, lantai, atap, Plafon, tanga, dinding partisi tetap, finishing, klading gedug dan komponen arsitektural dan structural lainya serya peralatan layan terpasang lain termasuk berat keran.SNI-1727-2013 Pasal 3.1.1. Beban mati yan digunakan pada design perencanaan ini adalah :

\section{Tabel Error! No text of specified style in document. .}

Beban mati

\begin{tabular}{llc}
\hline Bahan bangunan & \multicolumn{2}{c}{ Berat } \\
\hline Beton bertulang & 2.400 & $\mathrm{Kg} / \mathrm{m}^{3}$ \\
\hline Beton & 2.200 & $\mathrm{Kg} / \mathrm{m}^{3}$ \\
\hline Batu pecah & 1.450 & $\mathrm{Kg} / \mathrm{m}^{3}$ \\
\hline Pasangan batu merah & 1.700 & $\mathrm{Kg} / \mathrm{m}^{3}$ \\
\hline
\end{tabular}

Sumber :PPIUG 1983

Kombinasi dan faktor beban yang di pakai mengacu pada pasal 2.3.2 kombinasi dasar SNI 1727-2013, Sebagai Berikut :

- Kuat perlu terhadap beban Mati: $\mathrm{U}=1.4 \mathrm{D}$

- Kuat perlu terhadap Beban Mati dan Hidup: $\mathrm{U}=1.2 \mathrm{D}+1.6 \mathrm{~L}+0.5(\mathrm{~L}$ atau Satau $\mathrm{R})$

\section{Desain balance}

Kondisi regangan seimbang (balance reinforced). Kondisi yang terjadi pada suatu penampang ketika tulangan baja tarik mencapai regangan luluh, sedangkan beton yang tertekan mencapai regangan ultimatnya sebesar 0,003

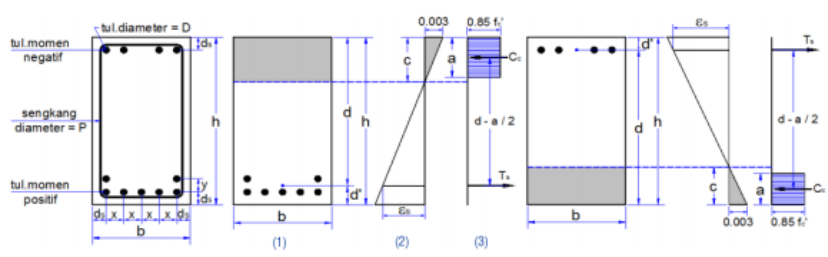

Gambar 2Analisa lentur pada penampang beton Sumber : https://jasaperencanaanstruktur.wordpress.com/home/

1) Penampang beton bertulang

2) Sebaran regangan pada penampang

3) Gaya-gaya dalam penampang dengan blok tegangan

persegi ekivalen.

Untuk menghitung kapasitas momen nominal adalah:

$M n=0,85 x f c^{0} x a \cdot b x\left(d-\frac{a}{2}\right)=A s \cdot f y x\left(\frac{a}{2}\right)$

Pada sebuah struktur beton bertulang akan terjadi runtuh apabila nilai $\varepsilon c^{\prime} \geq 0,003$ atau leleh pada baja tulanga apabila $\varepsilon s=\varepsilon y$.

Ragam kemungkinan keruntuhan struktur balok yang akan terjadi akibat desain penampang dan baja tulangan. 
1. Terjadi runtuh pada beton, namun kondisi baja tulangan masih belum leleh, kondisi ini disebut dengan keruntuhan tekan. Hal ini terjadi akibat baja tulangan yang terlalu kuat (over-reinforced).

2. Terjadi keruntuhan secara bersamanan antara beton dan baja tulangan, kondisi ini disebut dengan keruntuhan seimbang. Hal ini terjadi pada penampang Balok yang bertulangan seimbang (balanced reinforced).

3. Belum terjadi runtuh pada beton, namun baja tulangan sudah leleh, kondisi ini disebut dengan keruntuhan tarik. Hal ini terjadi pada penampang Balok yang bertulangan lemah (under-reinforced).

\section{METODOLOGI}

Tahapan pada penelitian ini digambarkan dalam bentuk diagram alir seperti terlihat pada gambar berikut:

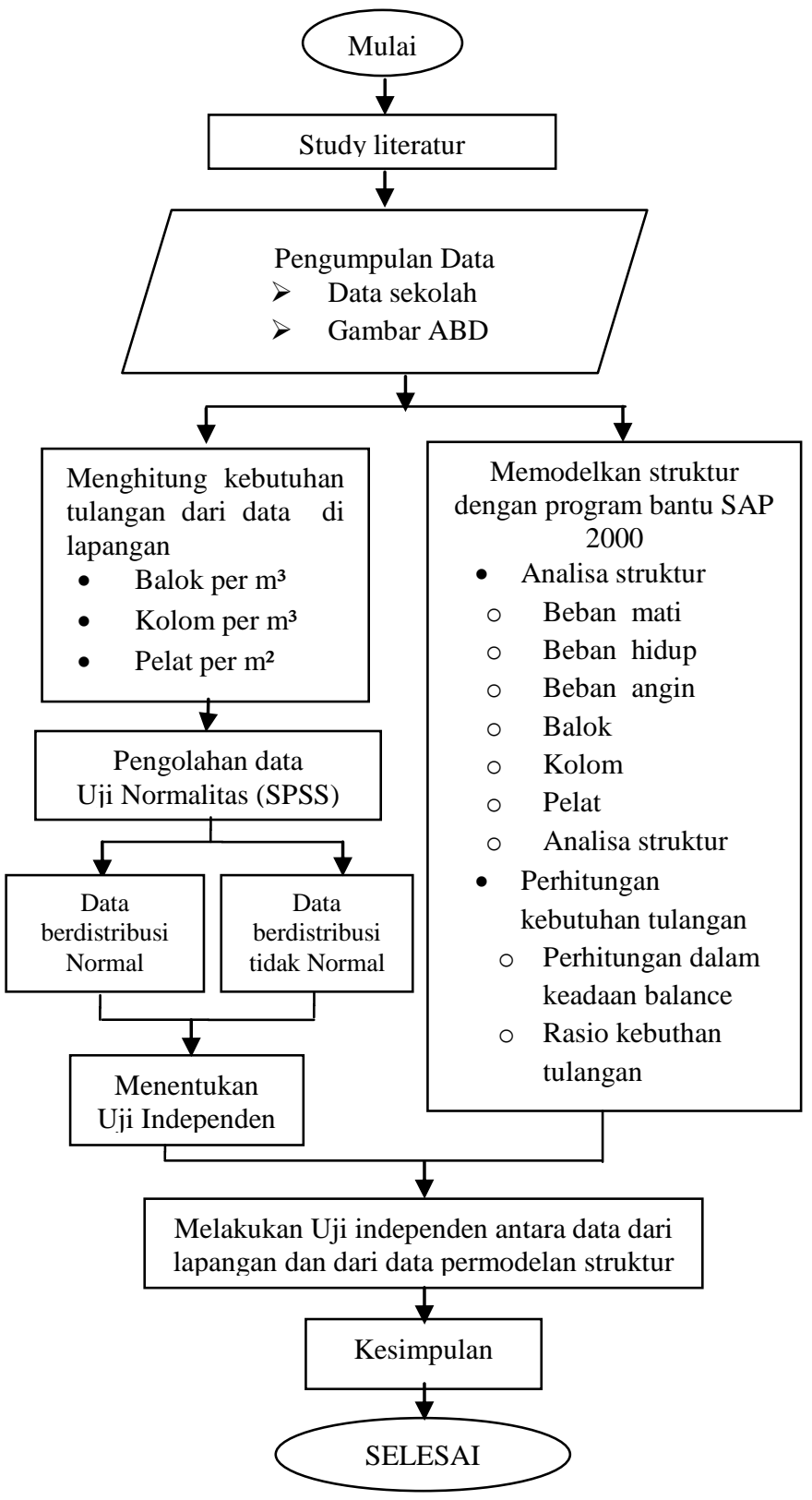

Gambar 1.Diagram Alir Penelitian

\section{HASIL PENELITIAN DAN PEMBAHASAN}

\section{Premilinary Design}

Komponen struktur yang terdapat pada bangunan yang meliputi pelat, kolom dan balok akan di rencanakan terlebih dahulu dimensi awal dari komponen struktur komponen bangunan (pra rencana)

Tabel 3.Premilinary design

\begin{tabular}{ll}
\hline Srtuktur & Dimensi \\
\hline Balok & $30 \times 50 \mathrm{~cm}$ \\
\hline Kolom & $35 \times 35 \mathrm{~cm}$ \\
\hline Pelat & $12 \mathrm{~cm}$ \\
\hline Sumber: Analisa data $(2018)$ &
\end{tabular}

\section{Hasil analisisi struktur}

Dari analisi yang telah di lakukan maka akan di dapat beberapa hasil dari analisis

Tabel 4.Tulangan struktur analisa desain balance

\begin{tabular}{|c|c|c|c|c|}
\hline \multirow{2}{*}{ Struktur } & \multirow{2}{*}{ Dimensi } & \multicolumn{3}{|c|}{ Tulangan } \\
\hline & & & Lapangan & Tumpuan \\
\hline \multirow{3}{*}{ Balok } & \multirow{3}{*}{$30 \times 60 \mathrm{~cm}$} & Atas & 8D-19 & 8D-19 \\
\hline & & Bawah & 8D-19 & 8D-19 \\
\hline & & Sengkang & $\emptyset 10-150$ & $\varnothing 10-150$ \\
\hline \multirow{2}{*}{ Kolom } & \multirow{2}{*}{$35 \times 35 \mathrm{~cm}$} & Utama & \multicolumn{2}{|c|}{ 16-D13 } \\
\hline & & Sengkang & \multicolumn{2}{|c|}{$\emptyset 10-120$} \\
\hline \multirow{2}{*}{ Pelat } & \multirow{2}{*}{$12 \mathrm{~cm}$} & Tarik & \multicolumn{2}{|c|}{$\emptyset 10-200$} \\
\hline & & Tekan & \multicolumn{2}{|c|}{$\varnothing 8-300$} \\
\hline
\end{tabular}

Sumber: Analisa data (2018)

\section{Perhitungan Berat Tulangan kolom, balok dan pelat di} lapangan dan perencanaan

Dari gambar ABD yang di dapat kita dapat melihat setiap tulangan yang ada pada balok,kolm serta pelat dari gambar tersebut kita menggunakan acuan perhitungan berat tulanga per $\mathrm{m}^{3}$.

Tabel 5.Tulangan struktur sampel gambar ABD

\begin{tabular}{|c|c|c|c|c|}
\hline \multirow{2}{*}{ Struktur } & \multirow{2}{*}{ Dimensi } & \multicolumn{3}{|c|}{ Tulangan } \\
\hline & & & Lapangan & Tumpuan \\
\hline \multirow{3}{*}{ Balok } & \multirow{3}{*}{$30 \times 60 \mathrm{~cm}$} & Atas & 4D-16 & 7D-16 \\
\hline & & Bawah & 7D-19 & 4D-19 \\
\hline & & Sengkang & $\emptyset 10-150$ & $\emptyset 10-150$ \\
\hline \multirow{2}{*}{ Kolom } & \multirow{2}{*}{$40 \times 40 \mathrm{~cm}$} & Utama & \multicolumn{2}{|c|}{ 12-D16 } \\
\hline & & Sengkang & \multicolumn{2}{|c|}{$\emptyset 10-150$} \\
\hline \multirow{2}{*}{ Pelat } & \multirow{2}{*}{$12 \mathrm{~cm}$} & Tarik & \multicolumn{2}{|c|}{$\emptyset 10-200$} \\
\hline & & Tekan & \multicolumn{2}{|c|}{$\varnothing 8-300$} \\
\hline
\end{tabular}

Sumber: Analisa data (2018) 


\section{Rekapitulasi hasil perhitungan analisa besi desain balance}

Perhitungan perencanaan kebutuhan besi yang di dapat ini akan di gunakan sebagai tolak ukur pembanding penggunaan besi di lapang dengan teori, pada Bab sebelumnya telah di jelaskan perhitungan kebutuhan tulangan, dan pada sub bab ini di di jelaskan perhitungan berat besi yang di gunakan sebagai nilai pembanding yang akan di sajikan pada tabel berikut:

Tabel 6. Rekapitulasi analisa perhitungan kebutuhan besi desain balance

\begin{tabular}{|c|c|c|c|}
\hline \multirow{3}{*}{$\begin{array}{c}\text { Perhitungan } \\
\text { Desain Balance }\end{array}$} & \multicolumn{3}{|c|}{ KEBUTUHAN BESI TULANGAN } \\
\hline & $\begin{array}{l}\text { Balok } \\
1\left(\mathbf{m}^{3}\right) \\
\end{array}$ & $\begin{array}{c}\text { Kolom } \\
\mathbf{1}\left(\mathbf{m}^{3}\right) \\
\end{array}$ & $\begin{array}{l}\text { Pelat } \\
1\left(\mathrm{~m}^{2}\right)\end{array}$ \\
\hline & 246,20 & 193,77 & 177,10 \\
\hline
\end{tabular}

Sumber : Analisa data (2018)

\section{Rekapitlasi hasil perhitungan analisa besi di lapangan}

Perhitungan analisa kebutuhan besi yang ada di lapangan dengan acuan gambar ABD yang di dapat, maka mendapatkan hasil perhitungan sebagai berikut:

Tabel 7. Rekapitulasi analisa perhitungan kebutuhan besi di lapangan

\begin{tabular}{lccc}
\hline & \multicolumn{3}{c}{ KEBUTUHAN BESI TULANGAN } \\
\cline { 2 - 4 } & $\begin{array}{c}\text { Balok } \\
1\left(\mathrm{~m}^{3}\right)\end{array}$ & $\begin{array}{c}\text { Kolom } \\
1\left(\mathrm{~m}^{3}\right)\end{array}$ & $\begin{array}{c}\text { Pelat } \\
1\left(\mathrm{~m}^{2}\right)\end{array}$ \\
\hline Rata-rata & 287.3 & 192.2 & 190.5 \\
\hline Selisih dalam \% & $16.7 \%$ & $-0.84 \%$ & $7.6 \%$ \\
\hline
\end{tabular}

Sumber : Analisa data (2018)

\section{Uji Normalitas}

Uji Normalitas dilakukan dengan tujuan untuk menilai sebaran data pada sebuah kelompok data atau variabel, apakah sebaran data tersebut berdistribusi normal ataukah tidak. Dengan bantuan program SPSS maka hasil uji normalitas di dapat sebagai berikut:

\section{NPar Tests}

[Dataset0]

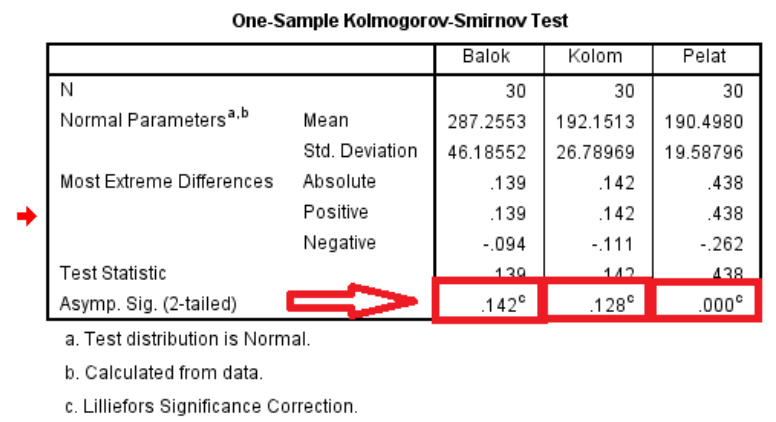

Gambar 3 Hasil Uji Normalitas menggunakan program SPSS

Sumber : Analisa data SPSS (2018)

\section{Statistik Parametik}

Pada ststistik parametik memiliki beberapa metode pengujian diantaranya adalah :

$$
\begin{aligned}
& \text { * Uji -z (1 atau } 2 \text { sampel) } \\
& \text { * Uji-T } \\
& \text { *olerasi person } \\
& \text { *ne or two-way anova parametik }
\end{aligned}
$$

Pada data parametik yang akan di gunakan untuk pengujian selanjutnya adalah Uji-T.

\section{Uji T}

Berdasarkan uji Normalitas di peroleh hasil bahwa data balok dan kolom berdistribusi Normal sehingga di gunakan uji T.

$>$ Balok

Menentukan Hipotesis

$\mathrm{H}_{0}=$ Rata-rata penulangan Balok $\leq 246,2$

$\mathrm{H}_{1}=$ Rata-rata penulanganBalok $>246,2$

$$
\begin{aligned}
& \text { /MISSING=ANALYSIS } \\
& / \text { VARIABLES }=\text { Balok }
\end{aligned}
$$$$
/ \text { CRITERIA }=\mathrm{CI}(.95)
$$

\section{$\Rightarrow$ T-Test}
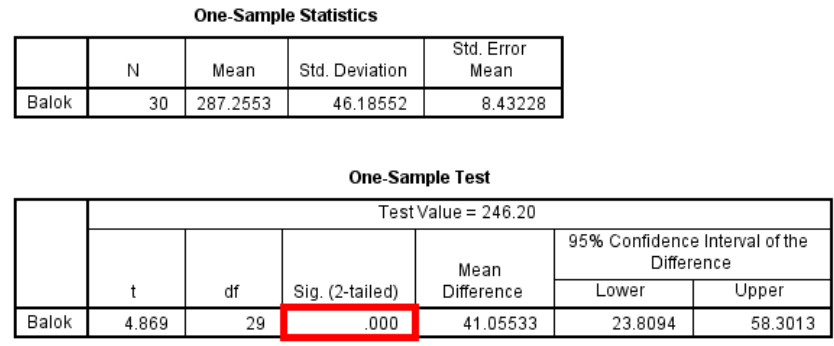

Gambar 4 Hasil Uji T test data balok menggunakan program SPSS

Sumber : Analisa data SPSS (2018)

Berdasarkan hasil output SPSS :

1. Jika nila sign. $(\mathrm{P})<0,05$ maka $\mathrm{H}_{0}$ Di tolak

2. Jika nila sign. $(\mathrm{P})>0,05$ maka $\mathrm{H}_{1}$ Di terima Pada pengujian data pelat nilai sign.(P) adalah 0,000 maka $\mathrm{H}_{0}$ di tolak dan $\mathrm{H}_{1}$ di terima.

$>$ Kolom

Menentukan Hipotesis

$\mathrm{H}_{0}$ =Rata-rata penulangan Kolom $\geq 193,77$ 


\section{$\Rightarrow$ T-Test}

[DataSet1] C: \Users \DJ\Documents\revisi.sav

One-Sample Statistics
\begin{tabular}{|c|r|c|r|c|}
\hline & \multicolumn{1}{|c|}{ N } & Mean & Std. Deviation & $\begin{array}{c}\text { Std. Error } \\
\text { Mean }\end{array}$ \\
\hline kolom & 30 & 192.1513 & 26.78969 & 4.89111 \\
\hline
\end{tabular}

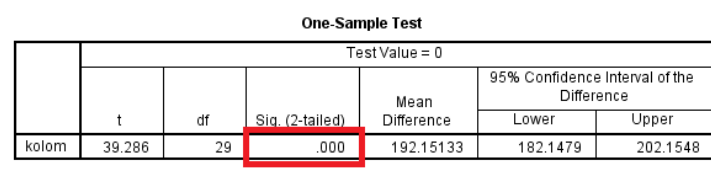

Gambar 5 Hasil Uji T test data kolom menggunakan program SPSS

Sumber : Analisa data SPSS (2018)

Berdasarkan hasil output SPSS :

1. Jika nila sign. $(\mathrm{P})<0,05$ maka $\mathrm{H}_{0}$ Di tolak

2. Jika nila sign. $(\mathrm{P})>0,05$ maka $\mathrm{H}_{1}$ Di terima

Pada pengujian data pelat nilai sign.(P) adalah 0,001 maka $\mathrm{H}_{0}$ di tolak dan $\mathrm{H}_{1}$ di terima.

\section{Statistik Non-Parametik}

Pada statistik Non parametik memiliki beberapa metode pengujian diantaranya adalah :
* Uji tanda (uji Binomial)
* Rank tanda
* Rank sum test
* Fisher probability exact test

Pada data Non Parametik yang akan di gunakan untuk pengujian selanjutnya adalah uji Binomial.

\section{Uji tanda (Uji Binomial)}

Berdasarkan uji normalitas di peroleh hasil bahwa data pelat tidak berdistribusi normal sehingga tidak dapat di gunakan uji T, sehingga di gunakan uji alternatif yaitu uji tanda (uji binomial).

\section{- Menentukan Hipotesis}

$\mathrm{H}_{0=}$ Rata-rata penulangan pelat $\leq 177,10$

$\mathrm{H}_{1=\text { Rata-rata penulangan pelat }>177,10}$

Hasil perhitungan uji binomial data pelat adalah sebagai berikut:

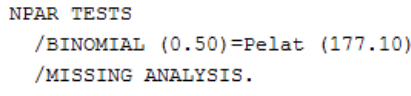

\section{$\Rightarrow$ NPar Tests}

\begin{tabular}{|ll|l|r|r|r|r|}
\multicolumn{7}{|c|}{ Binomial Test } \\
\hline & & Category & \multicolumn{1}{c|}{ N } & \multicolumn{1}{c|}{$\begin{array}{c}\text { Observed } \\
\text { Prop. }\end{array}$} & Test Prop. & $\begin{array}{c}\text { Exact Sig. (2- } \\
\text { tailed) }\end{array}$ \\
\hline Pelat & Group 1 & $<=177.1$ & 1 & .03 & .50 & .000 \\
& Group 2 & $>177.1$ & 29 & .97 & & \\
\hline & Total & & 30 & 1.00 & & \\
\hline
\end{tabular}

Gambar 6 Hasil Uji tanda data Pelat menggunakan program SPSS

Sumber : Analisa data SPSS (2018)
Berdasarkan hasil output SPSS :

1. Jika nila sign. $(\mathrm{P})<0,05$ maka $\mathrm{H}_{0}$ Di tolak

2. Jika nila sign. $(\mathrm{P})>0,05$ maka $\mathrm{H}_{1}$ Di terima

Pada pengujian data pelat nilai sign.(P) adalah 0,000 maka $\mathrm{H}_{0}$ di tolak dan $\mathrm{H}_{1}$ di terima.

\section{KESIMPULAN}

Berdasarkan dari pengolahan data yang di lakukan dengan program SPSS untuk membandingkan kebutuhan besi tulangan balok, kolom dan pelat di lapangan dengan teori perhitugan perencanaan, maka di dapat hasil sebagaimana berikut:

1. Berdasarkan teori perencanaan, di peroleh kebutuhan besi untuk struktur balok $246.20 \mathrm{~kg} / \mathrm{m}^{3}$, kolom $209,63 \mathrm{~kg} / \mathrm{m}^{3}$ dan pelat $177,10 \mathrm{~kg} / \mathrm{m}^{3}$.

2. Di bandingkan dengan besi terpasang di lapangan , pada balok lebih besar16.68\%, pada kolom lebih sedikit $-0,84 \%$ dan pada pelatlebih besar 7,56\%.

3. Berdasarkan uji statistik di peroleh sebagai berikut:

a. Nilai rata-rata pada penulangan balok adalah 287,255 sedang nilai sign. Adalah 0,000 sehingga dapatdi simpulkan bahwa penggunaan besi tulangan balok di lapangan lebih besar di banding dengan teori perencanaan.

b. Nilai rata-rata pada penulangan pelat adalah 192,151 sedang nilai sign. Adalah 0,001 < 0,05 sehingga dapat di simpulkan bahwa penggunaan besi tulangan kolom di lapangan lebih besar di banding dengan teori perencanaan.

\section{DAFTAR PUSTAKA}

Adiyono . 2006 menghitung konstruksi beton $.3^{\text {nd }}$ Jakarta:penebar swadaya

Asroni Ali, M T,2010kolom fondasi dan balok Tbeton bertulang Yogyakarta:graham ilmu

Ditjen Cipta Karya. 2002. Peraturan Beton Indonesia Tahun 2002. Jakarta: Ditjen Cipta Karya.

Ilmu sipil.http://www.ilmusipil.com/contoh-hitungkebutuhan-besi-untuk-cor-dak-lantai-beton di akses pada 12 desember 2017.

ModulSAP200.https://engineeringdesigncenter.files.wordp ress.com/2010/05/sap2000.pdfdi akses pada 12 februari 2018.

Nasution Amrinsyah . 2019 analisa dan desain struktur beton bertulang. Bandung ; ITB

Peraturan Pembebanan Indonesia Untuk Gedung 1983. 1983; Bandung:yayasan lembaga penyelidikan masalah bangunan.

perhitungan beton bertulang https://www.google.co.id/search?q=perhitungan+ kolom+beton+xls+download\&oq=perhitungan\&a qs=chrome.4.69i57j69i6012j69i61j69i59j35i39.56 91j0j7\&sourceid=chrome\&ie=UTF-8 di akses pada 25 November 2017.

Setiawan Agus . 2016 perencanaan struktur beton bertulang berdasarkan SNI 2847-2013 .Jakarta; Gelora Aksara Pratama

SNI 2847:2013 persyaratan beton struktral untuk bangunan gedung. 2013:Jakarta ;BSN 
SNI 1727 :2013 beban minimum untuk perencanaan bangunan gedung dan struktur. 2013:Jakarta ;BSN

Sugiharto toto, 2009 Analisis variansFakultas Ekonomi Universitas Gunadarma

Udji eko 2013. Perhitungan ulang struktur plasa Surabaya dengan metode. skripsi tidak di terbitkan, Program Studi Teknik Sipil . Universitas Muhammadiyah Surabya 